\title{
Feasibility of smaller arterial cannulas in venoarterial extracorporeal membrane oxygenation
}

Hiroo Takayama, MD, PhD, ${ }^{\text {a }}$ Elissa Landes, $\mathrm{MD},{ }^{\mathrm{a}}$ Lauren Truby, BS, ${ }^{\mathrm{a}}$ Kevin Fujita, BS, ${ }^{\mathrm{a}}$ Ajay J. Kirtane, MD, SM, ${ }^{\mathrm{b}}$ Linda Mongero, CCP, ${ }^{\mathrm{a}}$ Melana Yuzefpolskaya, MD, ${ }^{\mathrm{b}}$ Paolo C. Colombo, MD, ${ }^{\mathrm{b}}$ Ulrich P. Jorde, MD, ${ }^{\mathrm{b}}$ Paul A. Kurlansky, MD, ${ }^{\mathrm{a}}$ Koji Takeda, MD, PhD, ${ }^{\mathrm{a}}$ and Yoshifumi Naka, MD, PhD ${ }^{\mathrm{a}}$

Objectives: To facilitate venoarterial extracorporeal membrane oxygenation (ECMO) insertion for cardiogenic shock, we recently adopted a strategy of using a $15 \mathrm{~F}$ arterial cannula in all patients, rather than 1 designed to maximize flow. We aimed to compare the clinical outcomes of these 2 strategies.

Methods: In this retrospective study, 101 consecutive patients supported with ECMO via femoral cannulation between March 2007 and March 2013 were divided into 2 groups: Group L (17F-24F arterial cannula to accommodate full flow [ie, cardiac index of $2.5 \mathrm{~L} / \mathrm{m}^{2} / \mathrm{min}$ ]; $\left.\mathrm{n}=51\right)$ and Group $\mathrm{S}(15 \mathrm{~F}$ arterial cannula; $\mathrm{n}=50)$. The primary outcomes of interest were patients' overall status at 24 hours of support and cannulation-related adverse events.

Results: There were no significant differences in patient demographics, etiology of cardiogenic shock, or severity of illness before ECMO initiation between the 2 groups. Group L had significantly higher ECMO flow than Group $\mathrm{S}$ (flow index at 24 hours: $2.2 \pm 0.7 \mathrm{vs} 1.7 \pm 0.3 \mathrm{~L} / \mathrm{m}^{2} / \mathrm{min} ; P<.001$ ). However, there was no significant difference in use of vasoactive medication/hemodynamic parameters/laboratory parameters. Group L had higher incidence of cannulation-related adverse events $(35 \%$ vs $22 \%$ in Group S $[P=.14])$, particularly in cannulation site bleeding $(28 \%$ vs $10 \%[P=.03])$. Thirty-day survival was $55 \%$ in Group $\mathrm{L}$ versus $52 \%$ in Group $\mathrm{S}$ $(P=.77)$. Bleeding complication occurred in $53 \%$ in Group L versus $32 \%$ in Group $\mathrm{S}(P=.03)$.

Conclusions: Compared with the use of larger cannulas, ECMO with a $15 \mathrm{~F}$ arterial cannula appears to provide comparable clinical support with reduced bleeding complications. (J Thorac Cardiovasc Surg 2015;149:1428-33)

See related commentary pages 1434-5.

Despite significant progress in medical management, cardiogenic shock remains a disease entity with a high in-hospital mortality rate. Cardiogenic shock complicating acute myocardial infarction (the most common and widely studied etiology of cardiogenic shock) has been reported to carry a 30-day mortality ranging between $50 \%$ and $80 \% .^{1-3}$ In a recent prospective randomized control study, intraaortic balloon pump counterpulsation, the most widely used form of mechanical circulatory support, was shown to add no survival benefit when compared with medical management in this group of patients. ${ }^{1}$ Evolving mechanical circulatory support technology has been applied to address the unmet therapeutic needs of patients with cardiogenic shock. ${ }^{4}$ In fact, the

From the Departments of Surgery ${ }^{\mathrm{a}}$ and Medicine, ${ }^{\mathrm{b}}$ Columbia University Medical Center, New York, NY.

Disclosures: Authors have nothing to disclose with regard to commercial support.

Received for publication Oct 31, 2014; revisions received Jan 12, 2015; accepted for publication Jan 29, 2015; available ahead of print March 5, 2015.

Address for reprints: Hiroo Takayama, MD, PhD, 177 Fort Washington Ave, New York, NY 10032 (E-mail: hirofu2@hotmail.com).

$0022-5223 / \$ 36.00$

Copyright (c) 2015 by The American Association for Thoracic Surgery

http://dx.doi.org/10.1016/j.jtcvs.2015.01.042 updated American College of Cardiology/American Hospital Association guideline for the management of STelevation myocardial infarction states that "alternative left ventricular assist device (LVAD) for circulatory support may be considered in patients with refractory cardiogenic shock" as a Class IIb recommendation."

Durable LVAD technology has become the standard of care for patients with end-stage chronic heart failure, with established benefit in improving survival and quality of life of patients. ${ }^{6,7}$ However, the application of LVAD to acutely ill patients with cardiogenic shock has not been as successful. ${ }^{8,9}$ Durable LVADs have unfavorable characteristics as a cardiogenic shock therapeutic modality, including support limited to the left ventricle (unless a temporary right ventricular assist device is placed), prolonged time needed to establish support, and significant resource use (surgical team/equipment and cost). Instead, short-term mechanical circulatory support devices have been found to be more appropriate for this application. ${ }^{10-13}$ Among these, extracorporeal membrane oxygenation (ECMO) has increasingly been used for cardiopulmonary failure in adult patients. ${ }^{14-16}$ Unique features of venoarterial (VA) ECMO compared with other mechanical circulatory support devices, such as speed and ease of insertion, biventricular support, and simultaneous pulmonary support, make it an attractive 


\section{Abbreviations and Acronyms \\ $\mathrm{ECMO}=$ extracorporeal membrane oxygenation \\ LVAD $=$ left ventricular assist device \\ $\mathrm{VA}=$ venoarterial \\ VIS $=$ vasoactive-inotrope score}

modality for patients experiencing cardiogenic shock, especially when emergent support is needed.

This device is based on the principles of cardiopulmonary bypass developed for open heart surgery, and allows surgeons increased flexibility when compared with other devices, particularly in the selection of hardware such as cannulas, pump, and oxygenator as well as in the choice of procedural details such as access site and cannulation method. Despite these options, a paucity of evidence exists regarding optimal cannulation methodology.

An arterial cannula is conventionally chosen to accommodate calculated full flow, corresponding to a cardiac index of 2.2 to $2.5 \mathrm{~L} / \mathrm{m}^{2} / \mathrm{min}$. Whereas generating full flow from the VA ECMO circuit might have theoretical appeal, it is not always necessary and may, on occasion, even be detrimental. Increased left ventricular afterload with VA ECMO support can lead to left ventricular distension, pulmonary edema, hypoxia, and/or left ventricular thrombus formation. ${ }^{17,18}$ Reducing the VA ECMO flow rate and supporting the left ventricle with inotropes may be required to ameliorate this condition. In addition, femoral artery cannulation can cause arterial injury and subsequent limb ischemia, bleeding, thromboembolism, and other vascular complications. Surprisingly, very few published studies of ECMO use discuss or analyze the influence of flow rate on the outcome of support. Thus, an important question remains unanswered: What is the most appropriate flow with VA ECMO support in patients experiencing cardiogenic shock?

In an effort to balance the risks and benefits of a full-flow approach, our program changed the arterial cannulation strategy in November 2011 from the conventional approach (using a $15 \mathrm{~F}-24 \mathrm{~F}$ cannula) to 1 that used a smaller arterial cannula (ie, a $15 \mathrm{~F}$ cannula). The aim of our study was to compare the clinical outcomes of these 2 strategies. This study was unique in its focus on the detail of the ECMO logistics. Currently, VA ECMO is largely managed on the basis of what is believed to be the best practice, which is frequently based on a few centers' or individuals' experience. There is very limited evidence on the logistics of this therapy.

\section{METHODS}

This study was approved by our institutional review board with waiver of informed consent.

Among 146 patients who were placed on VA ECMO between March 2007 and March 2013, we retrospectively reviewed charts of 101 consecutive patients experiencing cardiogenic shock who underwent femoral vessel cannulation. Patients who underwent central aortic cannulation or axillary artery cannulation were excluded because arterial cannula selection in these configurations is not limited by the size of the artery and thus the same clinical concern does not exist. Before November 2011, the arterial cannula was selected among $15 \mathrm{~F}$ to $24 \mathrm{~F}$ cannulas to accommodate full-flow support (ie, cardiac index of $2.5 \mathrm{~L} / \mathrm{m}^{2} / \mathrm{min}$ ). Since then, the smaller, $15 \mathrm{~F}$ cannula has been the arterial cannula of choice. Group L included the 51 patients who received a $17 \mathrm{~F}$ to $24 \mathrm{~F}$ cannula and Group S included the 50 patients who received a $15 \mathrm{~F}$ cannula. In all cases, for venous drainage a $23 \mathrm{~F}$ femoral venous cannula was used except for a few cases in which a $21 \mathrm{~F}$ cannula was used at the surgeon's discretion because of the patient's small size.

\section{Patient Management Algorithm}

Our algorithm of bridge-to-decision device therapy for refractory cardiogenic shock during the study period has been previously described. ${ }^{19}$ Cardiogenic shock is treated with vasopressors and inotropes with or without addition of an intraaortic balloon pump. Refractory cardiogenic shock is characterized by a systolic blood pressure $<90 \mathrm{~mm} \mathrm{Hg}$, a cardiac index $<2.0 \mathrm{~L} / \mathrm{m}^{2} / \mathrm{min}$, pulmonary capillary wedge pressure $>16 \mathrm{~mm} \mathrm{Hg}$ (or evidence of pulmonary edema in the absence of a pulmonary artery catheter), and evidence of end-organ failure or the inability to be weaned from cardiopulmonary bypass for postcardiotomy shock despite the aforementioned measures. These patients are rapidly evaluated by our multidisciplinary mechanical circulatory support device heart team. Contraindications to mechanical circulatory support include the patient's or family's will against mechanical circulatory support, clinical judgment against mechanical circulatory support by the primary team, more than 30 minutes of ongoing cardiopulmonary resuscitation (from the beginning of the cardiopulmonary resuscitation until the arrival of the mechanical circulatory support device heart team at the bedside), septic shock, and extremely short-term predicted life expectancy due to comorbidities. A bridge-to-decision device (short-term external ventricular assist device or VA ECMO) is promptly placed. VA ECMO is preferred when a patient has unclear neurologic status due to prolonged cardiopulmonary resuscitation or other reasons, when hemodynamic parameters of a patient are too unstable to safely transfer the patient to the operating room, or when a patient has developed severe coagulopathy due to shock liver, potent antiplatelet therapy before percutaneous coronary intervention, or other causes.

VA ECMO is established through a percutaneous femoral arterial and venous cannulation or through a surgical cut-down. Although femoral vessel cannulation is preferred, central cannulation is used when the patient's chest is already open or when peripheral access is not attainable. Axillary arterial cannulation is chosen in selected cases. The choices of these procedural details are at the discretion of the attending physician. Only the patients with femoral cannulation were included in our study. The VA ECMO circuit consists of a Quadrox D oxygenator (Maquet, Rastatt, Germany), Rotaflow (Maquet, Rastatt, Germany), and Smart-coating tubing (Sorin, Milan, Italy).

Patients undergoing VA ECMO are managed in our specialized intensive care units. Tissue perfusion, monitored by mixed venous oxygen saturation, lactate, and end organ function, is optimized by adjusting the VA ECMO flow as well as by titrating the inotropic agents. Anticoagulation with heparin (goal partial thromboplastin time of 45-60 seconds) begins immediately after hemostasis is achieved. Patients are supported with mechanical ventilation and rested in bed. Sedation is transiently turned off each day to assess mental status. Hypothermia protocol with a goal temperature of $33^{\circ} \mathrm{C}$ to $34^{\circ} \mathrm{C}$ for 24 hours is implemented for patients with possible ischemic neurologic injury according to the decision of the multidisciplinary mechanical circulatory support device heart team, intensivists, and neurologists. Ipsilateral leg ischemia is closely monitored by confirming Doppler signals in the dorsalis pedis and/or posterior tibial artery. If the signal is lost, a distal perfusion cannula is inserted through a cut-down 
incision to the superficial femoral artery. Refractory left ventricular distension, defined as significant hypoxia due to cardiogenic pulmonary edema despite adjusting inotropes and VA ECMO flow, is treated with percutaneous insertion of Impella LVAD (AbioMed, Danvers, Mass) or placing a surgical left ventricular vent by inserting a cannula into the left ventricle through the left ventricular apex through a small left thoracotomy.

Once a patient stabilizes clinically, myocardial function and ability to be weaned from the VA ECMO are evaluated under echocardiographic and hemodynamic monitoring. In general, use of VA ECMO is limited to 7 days. VA ECMO can then be explanted if myocardial function recovers, or can be transitioned to a short-term versus implantable long-term mechanical circulatory support device. Exchange to a short-term ventricular assist device is chosen when the patient needs additional time for clinical stabilization before myocardial recovery or to more definitive heart replacement therapy.

\section{Definitions and Variables}

Myocardial recovery was defined as VA ECMO decannulation without any other type of heart replacement therapy and subsequent hospital discharge or survival to 30 days after the decannulation.

Demographics of interest were patient age, gender, and body mass index. Clinical comorbidities included a history of coronary artery disease, dyslipidemia, hypertension, and diabetes mellitus. The etiology of refractory cardiogenic shock in each patient was categorized as postcardiotomy shock, acute myocardial infarction, primary graft dysfunction following heart transplantation, acute decompensated heart failure, and other etiologies.

Hemodynamic parameters, laboratory values, vasopressor and inotrope use, as well as VA ECMO flow rates were collected immediately before the VA ECMO insertion and at 24 hours of VA ECMO support. The expanded vasoactive-inotrope score ie, dopamine dose $(\mu \mathrm{g} / \mathrm{kg} / \mathrm{min})+$ dobutamine dose $(\mu \mathrm{g} / \mathrm{kg} / \mathrm{min})+100 \times$ epinephrine dose $(\mu \mathrm{g} / \mathrm{kg} / \mathrm{min})+$ $10 \times$ milrinone dose $(\mu \mathrm{g} / \mathrm{kg} / \mathrm{min})+10,000 \times$ vasopressin dose $(\mathrm{U} / \mathrm{kg} /$ $\min )+100 \times$ norepinephrine dose $(\mu \mathrm{g} / \mathrm{kg} / \mathrm{min})^{20}$ was used to quantify the amount of cardiac support with vasopressors and inotropes. These detailed hemodynamic and laboratory data at 24 hours were available in 45 patients in each group.

Adverse events, including infection, cerebrovascular accident, and bleeding were defined according to the Interagency Registry for Mechanically Assisted Circulatory Support criteria. ${ }^{21}$ In addition, left ventricular distension was defined as need for intervention such as adding Impella LVAD or surgical left ventricular vent, and cannulation-related adverse events included cannulation-related bleeding requiring blood transfusion or procedures, ipsilateral limb ischemia, and need for cannula repositioning.

\section{Outcomes of Interest}

The main outcome of interest was hemodynamic and metabolic status as assessed by the laboratory profile at 24 hours of support as well as the incidence of cannulation-related adverse events. Other outcomes of interest were 30-day survival, next destination, and adverse events.

\section{Statistical Analysis}

Data are presented using mean values and standard deviations for continuous variables and percentages for categorical variables. Unpaired Fisher exact $t$ tests were used for comparison of means and Pearson $\chi^{2}$ test was used to compare categorical variables. Certain continuous variables were dichotomized using clinically appropriate thresholds. STATA SE version 13 (Stata Corp, College Station, Tex) was used for statistical analysis.

\section{RESULTS}

Demographic characteristics were similar between groups (Table 1). Comparing Group L and $\mathrm{S}$, mean age
TABLE 1. Baseline demographic characteristics of patients and etiology of cardiogenic shock

\begin{tabular}{lccc}
\hline Demographic characteristic & $\begin{array}{c}\text { Group L } \\
(\mathbf{n}=\mathbf{5 1})\end{array}$ & $\begin{array}{c}\text { Group S } \\
(\mathbf{n}=\mathbf{5 0})\end{array}$ & $\boldsymbol{P}$ value \\
\hline Male & $35(69)$ & $32(64)$ & .62 \\
Age, y & $56 \pm 15$ & $59 \pm 15$ & .37 \\
Body mass index & $29 \pm 8$ & $29 \pm 7$ & .72 \\
Body surface area, ${ }^{2}$ & $1.98 \pm 0.28$ & $1.95 \pm 0.23$ & .57 \\
Past medical history & & & \\
$\quad$ Coronary artery disease & $22(43)$ & $31(62)$ & .06 \\
Hypertension & $26(51)$ & $33(66)$ & .13 \\
Hyperlipidemia & $15(29)$ & $23(46)$ & .09 \\
Diabetes mellitus & $17(33)$ & $16(32)$ & .89 \\
Chronic obstructive pulmonary & $7(14)$ & $5(10)$ & .56 \\
$\quad$ disorder & & & \\
$\quad$ Prior cerebrovascular accident & $2(4)$ & $6(12)$ & .13 \\
Etiology of shock & & & \\
Postcardiotomy shock & $9(18)$ & $14(28)$ & .22 \\
Acute myocardial infarction & $17(33)$ & $17(34)$ & .94 \\
Acute decompensated heart & $7(14)$ & $9(18)$ & .56 \\
$\quad$ failure & & & \\
Graft failure posttransplant & $8(16)$ & $3(6)$ & .12 \\
Other & $10(20)$ & $7(14)$ & .45 \\
\hline
\end{tabular}

Values are presented as $\mathrm{n}(\%)$ or mean \pm standard deviation.

was $56 \pm 15$ years versus $59 \pm 15$ years $(P=.37)$ and male gender was $69 \%$ versus $64 \%(P=.62)$. Past medical histories of coronary artery disease, diabetes, and cerebrovascular accident were present in $43 \%, 33 \%$, and $4 \%$, respectively, in Group L and $62 \%, 32 \%$, and $12 \%$, respectively, in Group $\mathrm{S}(P=.06, P=.89$, and $P=.13$, respectively). Etiology of cardiogenic shock was not significantly different between the groups (Table 1).

The severity of acute illness immediately before the VA ECMO support was similar between groups (Table 2). Twenty-five percent of patients in Group L and 34\% in Group $\mathrm{S}$ were undergoing active cardiopulmonary resuscitation. VIS ( $38.2 \pm 26.6$ in Group L vs $41.6 \pm 35.6$ in Group $\mathrm{S} ; P=.63)$ and frequency of VIS $>20(75 \%$ in Group L vs $72 \%$ in Group $S ; P=.38$ ) were similar as was severity of lactic acidosis.

TABLE 2. Severity of acute illness

\begin{tabular}{lccc}
\hline \multicolumn{1}{c}{ Illness } & $\begin{array}{c}\text { Group L } \\
(\mathbf{n}=\mathbf{5 1})\end{array}$ & $\begin{array}{c}\text { Group S } \\
(\mathbf{n = 5 0 )}\end{array}$ & $\boldsymbol{P}$ value \\
\hline Intraaortic balloon pulsation & $19(37)$ & $22(44)$ & .49 \\
Impella & $3(6)$ & $5(10)$ & .49 \\
Active cardiopulmonary & $13(25)$ & $17(34)$ & .35 \\
$\quad$ resuscitation & & & \\
Vasoactive-inotrope score $>20$ & $30(75)$ & $28(72)$ & .75 \\
Lactate, mmol/L & $5.2 \pm 4.5$ & $6.2 \pm 3.6$ & .34 \\
pH & $7.38 \pm 0.34$ & $7.31 \pm 0.13$ & .24 \\
Blood urea nitrogen, mg/dL & $35 \pm 19$ & $36 \pm 23$ & .87 \\
Creatinine, mg/dL & $1.9 \pm 1.0$ & $1.9 \pm 1.4$ & .83 \\
Total bilirubin, mg/dL & $2.2 \pm 2.7$ & $1.6 \pm 1.5$ & .18 \\
\hline
\end{tabular}

Values are presented as $\mathrm{n}(\%)$ or $\mathrm{n} \pm$ standard deviation. 
TABLE 3. Procedure details

\begin{tabular}{lrcc}
\hline Procedure detail & $\begin{array}{r}\text { Group L } \\
(\mathbf{n}=\mathbf{5 1})\end{array}$ & $\begin{array}{l}\text { Group S } \\
(\mathbf{n}=\mathbf{5 0})\end{array}$ & $\boldsymbol{P}$ value \\
\hline Location & & & \\
$\quad$ Bedside & $16(31)$ & $29(58)$ & .007 \\
Catheterization lab & $6(12)$ & $13(26)$ & .07 \\
Operating room & $22(43)$ & $7(14)$ & .001 \\
$\quad$ Unknown & $7(14)$ & $1(2)$ & .03 \\
Technique & & & .00 \\
$\quad$ Percutaneous & $22(43)$ & $44(88)$ & \\
$\quad$ Surgical cut-down & $29(57)$ & $6(12)$ & \\
\hline
\end{tabular}

Values are presented as $\mathrm{n}(\%)$.

Cannulation for VA ECMO was performed at the bedside, in the catheterization laboratory, or in the operating room (Table 3). Cannulation was performed more often at the bedside in Group S (31\% vs $58 \% ; P=.007)$ and more commonly in the operating room in Group L (43\% vs $14 \% ; P=.001)$. Because the baseline etiology of cardiogenic shock and acute illness were not different between the groups, this difference is likely related to more frequent use of surgical cut-down in Group L ( $57 \%$ vs $12 \%$ in Group S; $P<.001)$.

\section{Status at 24 Hours}

At 24 hours of VA ECMO support, the requirement for vasoactive medication was reduced in both groups but was similar between groups (VIS $26.2 \pm 22.2$ in Group L vs $19.9 \pm 19.3$ in Group $S ; P=.18$ ) despite higher flows in Group L. The individual inotropic requirement in each group was as follows (Group L vs Group S): epinephrine $3.7 \pm 6.9$ versus $1.1 \pm 2.2 \mu \mathrm{g} / \mathrm{min}(P=.02)$, dobutamine $1.3 \pm 3.1$ versus $1.9 \pm 2.9 \mu \mathrm{g} / \mathrm{kg} / \mathrm{min}(P=.40)$, and milrinone $0.20 \pm 0.20$ versus $0.10 \pm 0.15 \mu \mathrm{g} / \mathrm{kg} / \mathrm{min}(P=.28)$. The flow rates at initiation were $3.9 \pm 0.1$ in Group $\mathrm{L}$ and $3.2 \pm 0.7$ in Group $\mathrm{S}(P=.0001)$ with indices of $2.0 \pm$ 0.1 and $1.7 \pm 0.4$, respectively $(P=.0003)$. At 24 hours flow rates were $4.4 \pm 1.3$ and $3.2 \pm 0.6(P=.0001)$, with flow indices of $2.2 \pm 0.7$ and $1.7 \pm 0.3(P=.0003)$. With this level of support, there was no difference in the hemodynamic or laboratory profile between groups (Table 4).

\section{Cannulation-related Adverse Events}

Cannulation-related adverse events occurred in $25 \%$ of patients in Group L and in $22 \%$ in patients in Group S $(P=.14)$ (Table 5). Cannulation site bleeding was significantly more frequent in Group L $(28 \%$ vs $10 \%$; $P=.025)$. This difference was not associated with the cannulation technique (cut-down vs percutaneous). There was an approximately $30 \%$ incidence of site bleed in Group L regardless of the technique (cut-down: 8 out of 29 [28\%] and percutaneous: 6 out of 22 [33\%]). Site bleeding occurred only with the percutaneous technique in Group S. Cannulation-related adverse events are summarized in Table 6. Distal perfusion cannula was used in $19 \%$ of patients in Group L and in 18\% of patients in Group S.
TABLE 4. Patient status at 24 hours of vanoarterial extracorporeal membrane oxygenation (VA ECMO) support

\begin{tabular}{|c|c|c|c|c|c|}
\hline & $\begin{array}{l}\text { Group L } \\
(n=45)\end{array}$ & n & $\begin{array}{l}\text { Group } S \\
(n=45)\end{array}$ & $\mathbf{n}$ & $\begin{array}{c}P \\
\text { value } \\
\end{array}$ \\
\hline VA ECMO flow, $\mathrm{L} / \mathrm{min}$ & $4.4 \pm 1.3$ & 41 & $3.2 \pm 0.6$ & 37 & .0001 \\
\hline VA ECMO flow index, $\mathrm{L} / \mathrm{m}^{2} / \mathrm{min}$ & $2.2 \pm 0.7$ & 41 & $1.7 \pm 0.3$ & 37 & .0003 \\
\hline Vasoactive-inotrope score $>20, \%$ & 48 & 40 & 38 & 40 & .38 \\
\hline \multicolumn{6}{|l|}{ Hemodynamic parameters } \\
\hline Heart rate, beats/min & $88 \pm 18$ & 45 & $85 \pm 20$ & 43 & .53 \\
\hline Mean arterial pressure, $\mathrm{mm} \mathrm{Hg}$ & $74 \pm 16$ & 39 & $81 \pm 16$ & 43 & .06 \\
\hline $\begin{array}{l}\text { Mean pulmonary artery pressure, } \\
\text { mm Hg }\end{array}$ & $22 \pm 10$ & 22 & $21 \pm 8$ & 32 & .55 \\
\hline Central venous pressure, $\mathrm{mm} \mathrm{Hg}$ & $11 \pm 5$ & 44 & $10 \pm 4$ & 40 & .19 \\
\hline Mixed venous oxygen saturation, $\%$ & $80 \pm 14$ & 14 & $73 \pm 11$ & 28 & .07 \\
\hline \multicolumn{6}{|c|}{ Laboratory values } \\
\hline Lactate, $\mathrm{mmol} / \mathrm{L}$ & $3.9 \pm 4.8$ & 37 & $4.4 \pm 4.5$ & 30 & .69 \\
\hline $\mathrm{pH}$ & $7.4 \pm 0.9$ & 44 & $7.4 \pm 0.9$ & 44 & .35 \\
\hline Blood urea nitrogen, $\mathrm{mg} / \mathrm{dL}$ & $31 \pm 14$ & 44 & $31 \pm 14$ & 45 & .94 \\
\hline Creatinine, $\mathrm{mg} / \mathrm{dL}$ & $1.8 \pm 1.0$ & 44 & $1.6 \pm 0.9$ & 45 & .37 \\
\hline Total bilirubin, $\mathrm{mg} / \mathrm{dL}$ & $4.1 \pm 0.6$ & 43 & $2.9 \pm 0.4$ & 43 & .09 \\
\hline
\end{tabular}

Values are presented as mean \pm standard deviation unless otherwise noted.

\section{Other Outcomes}

Other important clinical outcomes were likewise similar between groups (Table 7). Mean length of the support was $3.9 \pm 4.4$ days in Group L versus $3.7 \pm 2.7$ days in Group $\mathrm{S}(P=.74)$. Median length of the support was 3.4 (interquartile range, 1.0-6.1) days in Group L versus 3.1 (interquartile range, 1.9-5.1) days in Group $\mathrm{S}(P=.81)$. Thirty-day survival was $55 \%$ versus $52 \%(P=.77)$. Next destination after the VA ECMO (Group L vs Group S) was transition to ventricular assist device (35\% vs $38 \%$ ) and myocardial recovery $(24 \%$ vs $24 \%)$. Death during VA ECMO support occurred in $31 \%$ of patients in Group L versus $28 \%$ of patients in Group S.

\section{Other Adverse Events}

Adverse events while on support are described in Table 6. Importantly, bleeding was more common in Group L; that is, $53 \%$ compared with $32 \%$ in Group $\mathrm{S}(P=.03)$. Overall incidence of cerebrovascular accident was low with no significant intergroup difference. left ventricular distension was not uncommon and there was no intergroup difference ( $16 \%$ in Group L vs $20 \%$ in Group S; $P=.57$ ).

TABLE 5. Cannulation-related adverse events

\begin{tabular}{lccc}
\hline \multicolumn{1}{c}{ Adverse event } & $\begin{array}{c}\text { Group L } \\
(\mathbf{n}=\mathbf{5 1})\end{array}$ & $\begin{array}{c}\text { Group S } \\
(\mathbf{n}=\mathbf{5 0})\end{array}$ & $\boldsymbol{P}$ value \\
\hline Cannulation-related adverse event & $18(35)$ & $11(22)$ & .14 \\
Cannulation site bleeding & $14(28)$ & $5(10)$ & .025 \\
Suspected retroperitoneal bleeding & $6(12)$ & $6(12)$ & .97 \\
Ischemic leg & $2(4)$ & $2(4)$ & .98 \\
Need for cannula repositioning & $4(8)$ & $3(6)$ & .71 \\
\hline
\end{tabular}

Values are presented as $\mathrm{n}(\%)$. 
TABLE 6. Other adverse events

\begin{tabular}{lccc}
\hline \multicolumn{1}{c}{ Adverse event } & $\begin{array}{c}\text { Group L } \\
(\mathbf{n = 5 1 )}\end{array}$ & $\begin{array}{c}\text { Group S } \\
(\mathbf{n}=\mathbf{5 0 )}\end{array}$ & $\boldsymbol{P}$ value \\
\hline Infection & $7(14)$ & $7(14)$ & .97 \\
Cerebrovascular accident & $2(4)$ & $3(3)$ & .68 \\
Left ventricle distension & $8(16)$ & $10(20)$ & .57 \\
Bleeding & $27(53)$ & $16(32)$ & .03 \\
$\quad$ Interagency Registry for Mechanically & $19(37)$ & $12(24)$ & .15 \\
$\quad$ Assisted Circulatory Support-defined & & & \\
$\quad$ bleeding & & & \\
$\quad$ Cannulation site bleeding & $14(28)$ & $5(10)$ & .03 \\
\hline
\end{tabular}

Values are presented as $\mathrm{n}(\%)$.

\section{Small Cannula for Large Patients?}

To address the effect of the body size, Group $\mathrm{S}$ was divided into 2 groups: body surface area $\leq 1.92(\mathrm{n}=26)$ versus body surface area $>1.92(\mathrm{n}=25)$. At 24 hours, the flow was $3.1 \pm 0.6$ versus $3.4 \pm 0.5 \mathrm{~L} / \mathrm{min}(P=.13)$, mixed venous oxygen saturation was $74 \% \pm 12 \%$ versus $71 \% \pm 11 \%(P=.49)$, lactate was $5.6 \pm 5.8 \mathrm{mmol} / \mathrm{L}$ versus $3.7 \pm 3.1 \mathrm{mmol} / \mathrm{L}(P=.25)$, and 30-day mortality was $44 \%$ versus $62 \%(P=.07)$.

\section{DISCUSSION}

Review of our experience with the use of a $15 \mathrm{~F}$ cannula versus a larger arterial cannula for VA ECMO support in patients experiencing cardiogenic shock supports the findings that this approach provides similar hemodynamic benefit despite lower actual flow rates and results in fewer bleeding complications.

VA ECMO support for patients experiencing cardiogenic shock has become increasingly more common, with several large series reported. We recently reported the outcomes of this approach in 179 patients with a 30-day survival rate of $45 \%{ }^{22}$ Fletcher and colleagues, ${ }^{23}$ in 1 of the largest series, including 260 patients, also reported a 30-day survival rate of $41 \%$. In a meta-analysis of 1763 patients the 30-day survival rate ranged from $21 \%$ to $65 \%$ (mean $41 \%$ ). ${ }^{24}$ Comparing these outcome data is complicated because of differences in patient demographic characteristics and acuity of illness. For instance, the percentage of the patients who were undergoing active cardiopulmonary resuscitation at the time of VA ECMO insertion was $15 \%$ in the Fletcher

TABLE 7. Other clinical outcomes

\begin{tabular}{|c|c|c|c|}
\hline Outcome & $\begin{array}{l}\text { Group L } \\
(\mathbf{n}=\mathbf{5 1})\end{array}$ & $\begin{array}{l}\text { Group S } \\
(\mathbf{n}=\mathbf{5 0})\end{array}$ & $P$ value \\
\hline Length of support, $d$ & $3.9 \pm 4.4$ & $3.7 \pm 2.7$ & .74 \\
\hline 30-d survival & $28(55)$ & $26(52)$ & .77 \\
\hline Survival to discharge & $31(61)$ & $27(54)$ & .49 \\
\hline \multicolumn{4}{|l|}{ Next destination } \\
\hline $\begin{array}{l}\text { Death on vanoarterial extracorporeal } \\
\text { membrane oxygenation }\end{array}$ & $21(41)$ & $19(38)$ & .74 \\
\hline Myocardial recovery & $12(24)$ & $12(24)$ & 96 \\
\hline Transition to ventricular assist device & $18(35)$ & $19(38)$ & .78 \\
\hline
\end{tabular}

Values are presented as mean \pm standard deviation or $\mathrm{n}(\%)$. and colleagues series ${ }^{23}$ whereas that was $31 \%$ in our series. Analysis is further complicated by the lack of uniform definitions or classifications of refractory cardiogenic shock. Importantly, differences in practice patterns in managing patients receiving VA ECMO can make comparison between centers challenging.

Nonetheless, these reported outcomes of the VA ECMO support are frequently considered satisfactory given the moribund condition of these acutely ill patients. To objectively assess and understand the effect of VA ECMO and establish its appropriate therapeutic role in cardiogenic shock, attention to the details of patient management becomes crucial. Our study is novel in its focus on 1 important technical aspect of patient management and its physiologic and clinical ramifications.

On the basis of this review of our experience, our current arterial cannula of choice is a $15 \mathrm{~F}$ arterial cannula regardless of the calculated full flow.

The patients in Group L received higher flow rate compared with those in Group S; however, this was not translated into clear clinical benefit at 24 hours of support. None of the hemodynamic parameters, requirement for vasoactive medications, or laboratory values showed a significant difference with this approach. Interestingly the mean flow index at 24 hours of support in Group L was $2.2 \pm 0.7 \mathrm{~L} / \mathrm{m}^{2} / \mathrm{min}$, although the arterial cannula had been chosen to allow for a more generous flow rate. We do not believe this lower-than-expected flow rate compromised the outcomes of the patients in Group L. Providing full flow in VA ECMO is sometimes deleterious due to left ventricular distension. Rather, optimizing the VA ECMO flow and inotropic support to achieve adequate tissue perfusion and to enhance left ventricular contraction for left ventricular emptying is the key to stabilizing VA ECMO support, and this lower flow rate is reflective of this practice.

More fundamental than the issue of cannula size is this question: What is the appropriate flow rate (index) with VA ECMO support? Although not specifically designed to address this subject, the flow index of $1.7 \mathrm{~L} / \mathrm{m}^{2} / \mathrm{min}$ provided in Group $\mathrm{S}$ appeared to have achieved fairly equivalent clinical outcomes with the flow index of $2.2 \mathrm{~L} / \mathrm{m}^{2}$ / min provided in Group L. Several issues require attention. First, the higher complication rate in Group L might have offset the potential advantage of higher flow. Second, our sample size is small. The study is not adequately powered to identify a noninferiority of any of the outcomes between the groups. Third, use of the Impella LVAD for left ventricular distension (14\% in Group L and $20 \%$ in Group S) obviously increased the total sum of flow rate through the devices but this was not taken into consideration for the analysis. This was not possible because of inability to accurately measure the flow rate of the Impella LVAD.

The major benefit of using the smaller cannula was fewer incidences of vascular complications. Incidence of 
cannulation site bleeding was less than half ( $28 \%$ in Group L vs $10 \%$ in Group S). In a meta-analysis by Cheng and colleagues, ${ }^{24}$ the reported cumulative rate of major or significant bleeding was $46 \%$ (120 out of 260) with a pooled estimate rate of $40.8 \%$ (95\% confidence interval, $26.8 \%$ $56.6 \%$ ). Efforts to decrease major bleeding are critical in improving outcomes of VA ECMO support, and our study suggests that using a $15 \mathrm{~F}$ cannula could contribute to this end. Although more patients in Group L had undergone surgical cut-down, our further analysis suggested that the difference in bleeding incidence was not due to the approach (surgical cut-down vs percutaneous). We speculate the reason for more liberal use of the percutaneous approach in Group $\mathrm{S}$ was because of more aggressive use of VA ECMO (requiring emergent insertion preferring percutaneous approach) and increased comfort level of the providers over time, especially with a smaller cannula.

Other unmeasured potential benefits to the use of a smaller cannula include the improved ability to obtain arterial access in patients with hypotension or without a pulse as well as in obese patients or those with a small artery. Easier cannulation requires less experience and training, and thus could potentially increase the pool of providers who can perform the VA ECMO insertion procedure.

There are several limitations in this study. Most importantly, these observed outcomes were the result of the patient management practice in our program. Currently there are no recommended best practice guidelines in managing patients receiving VA ECMO, and therefore our findings may not be applicable or relevant to other programs in which the management strategy is significantly different. For instance, for programs in which axillary artery cannulation with a chimney graft is preferred, our discussion of femoral artery cannulation is of less importance.

Although the 2 groups were created from consecutive patients around the time of the change in our practice of arterial cannula selection, this historical comparison could have introduced unmeasured biases. Lastly, this retrospective study contains the same inherited limitations as other retrospective studies.

\section{CONCLUSIONS}

ECMO with a $15 \mathrm{~F}$ arterial cannula appears to provide hemodynamic support that is comparable in its clinical benefit to that obtained from larger cannulas while resulting in fewer bleeding complication.

\section{References}

1. Thiele H, Zeymer U, Neumann FJ, Ferenc M, Olbrich HG, Hausleiter J, et al. Intraaortic balloon support for myocardial infarction with cardiogenic shock. $N$ Engl J Med. 2012;367:1287-96.

2. Holmes DR Jr, Berger PB, Hochman JS, Granger CB, Thompson TD, Califf RM, et al. Cardiogenic shock in patients with acute ischemic syndromes with and without ST-segment elevation. Circulation. 1999;100:2067-73.
3. Takayama H, Truby L, Koekort M, Uriel N, Colombo P, Mancini DM, et al. Clinical outcome of mechanical circulatory support for refractory cardiogenic shock in the current era. J Heart Lung Transplant. 2013;32:106-11.

4. O'Connor CM, Rogers JG. Evidence for overturning the guidelines in cardiogenic shock. N Engl J Med. 2012;367:1349-50.

5. O'Gara PT, Kushner FG, Ascheim DD, Casey DE Jr, Chung MK, de Lemos JA, et al. 2013 ACCF/AHA guideline for the management of ST-elevation myocardial infarction: a report of the American College of Cardiology Foundation/ American Heart Association Task Force on Practice Guidelines. Circulation. 2013; 127:e362-425.

6. Jorde UP, Kushwaha SS, Tatooles AJ, Naka Y, Bhat G, Long JW, et al. Results of the destination therapy post-food and drug administration approval study with a continuous flow left ventricular assist device: a prospective study using the INTERMACS registry (Interagency Registry for Mechanically Assisted Circulatory Support). J Am Coll Cardiol. 2014;63:1751-7.

7. Slaughter MS, Rogers JG, Milano CA, Russell SD, Conte JV, Feldman D, et al. Advanced heart failure treated with continuous-flow left ventricular assist device. N Engl J Med. 2009;361:2241-51.

8. Boyle AJ, Ascheim DD, Russo MJ, Kormos RL, John R, Naka Y, et al. Clinical outcomes for continuous-flow left ventricular assist device patients stratified by preoperative INTERMACS classification. J Heart Lung Transplant. 2011;30:402-7.

9. Kirklin JK, Naftel DC, Pagani FD, Kormos RL, Stevenson LW, Blume ED, et al. Sixth INTERMACS annual report: a 10,000-patient database. J Heart Lung Transplant. 2014;33:555-64.

10. John R, Long JW, Massey HT, Griffith BP, Sun BC, Tector AJ, et al. Outcomes of a multicenter trial of the Levitronix CentriMag ventricular assist system for shortterm circulatory support. J Thorac Cardiovasc Surg. 2011;141:932-9.

11. Worku B, Naka Y, Pak SW, Cheema FH, Siddiqui OT, Jain J, et al. Predictors of mortality after short-term ventricular assist device placement. Ann Thorac Surg. 2011;92:1608-12; discussion 12-3.

12. Takayama H, Soni L, Kalesan B, Truby LK, Ota T, Cedola S, et al. Bridge-to-decision therapy with a continuous-flow external ventricular assist device in refractory cardiogenic shock of various etiologies. Circ Heart Fail. 2014;7:799-806.

13. Lauten A, Engstrom AE, Jung C, Empen K, Erne P, Cook S, et al. Percutaneous leftventricular support with the Impella-2.5-assist device in acute cardiogenic shock: results of the Impella-EUROSHOCK-registry. Circ Heart Fail. 2013;6:23-30.

14. Lazzeri C, Bernardo P, Sori A, Innocenti L, Stefano P, Peris A, et al. Venous-arterial extracorporeal membrane oxygenation for refractory cardiac arrest: a clinical challenge. Eur Heart J Acute Cardiovasc Care. 2013;2:118-26.

15. Glod SA. A piece of my mind. Miracle. JAMA. 2014;311:1499.

16. Paden ML, Conrad SA, Rycus PT, Thiagarajan RR, Registry E. extracorporeal life support organization registry report 2012. ASAIO J. 2013;59:202-10.

17. Koeckert MS, Jorde UP, Naka Y, Moses JW, Takayama H. Impella LP 2.5 for left ventricular unloading during venoarterial extracorporeal membrane oxygenation support. J Cardiovasc Surg. 2011;26:666-8.

18. Seib PM, Faulkner SC, Erickson CC, Van Devanter SH, Harrell JE, Fasules JW, et al. Blade and balloon atrial septostomy for left heart decompression in patients with severe ventricular dysfunction on extracorporeal membrane oxygenation. Catheter Cardiovasc Interv. 1999;46:179-86.

19. Takayama H, Truby L, Koekort M, Uriel N, Colombo P, Mancini D, et al. Clinical outcome of mechanical circulatory support for refractory cardiogenic shock in the current era. J Heart Lung Transplant. 2013;32:106-11.

20. Gaies M, Gurney JG, Yen AH, Napoli ML, Gajarski RJ. Vasoactive-inotropic score as a predictor of morbidity and mortality in infants after cardiopulmonary bypass. Pediatr Crit Care Med. 2010;11:234-8.

21. Casas F, Reeves A, Dudzinski D, Weber S, Lorenz M, Akiyama M, et al. Performance and reliability of the $\mathrm{CPB} / \mathrm{ECMO}$ initiative forward lines casualty management system. ASAIO J. 2005;51:681-5.

22. Mundy LT, Hongo T, Kirtane A, Mongero L, Landes E, Yuzefpolskaya M, et al. The Columbia experience of 163 patients with venoarterial extracorporeal membranous oxygenation for refractory cardiogenic shock. J Heart Lung Transplant. 2014;33:S38-9.

23. Flecher E, Anselmi A, Corbineau H, Langanay T, Verhoye JP, Felix C, et al. Current aspects of extracorporeal membrane oxygenation in a tertiary referral centre: determinants of survival at follow-up. Eur J Cardiothorac Surg. 2014;46:665-71.

24. Cheng R, Hachamovitch R, Kittleson M, Patel J, Arabia F, Moriguchi J, et al. Complications of extracorporeal membrane oxygenation for treatment of cardiogenic shock and cardiac arrest: a meta-analysis of 1,866 adult patients. Ann Thorac Surg. 2014;97:610-6.

Key Words: cardiogenic shock, ECMO, complications 